\title{
Timely initiation of postpartum contraceptive and associated factors among women of extended postpartum period in Pawe district, northwest Ethiopia, 2019
}

Desalegn Nazi Jaleta ( $\sim$ desalegnnazi9@gmail.com )

Assosa University

Hedeja Yenus Yeshita

University of Gondar College of Medicine and Health Sciences

Koku Sisay Tamirat

University of Gondar College of Medicine and Health Sciences

Research article

Keywords: Postpartum, timely initiation, contraceptive, factors, Pawe district, Ethiopia

Posted Date: October 7th, 2019

DOI: https://doi.org/10.21203/rs.2.15665/v1

License: (9) This work is licensed under a Creative Commons Attribution 4.0 International License.

Read Full License 


\section{Abstract}

Background: Postpartum family planning is an important intervention for reducing high risk fertility behavior and spacing birth intervals; which ultimately helpful for the health of mothers and their babies. Hence, this study aimed to determine the magnitude of timely initiation of postpartum contraceptive and associated factors among extended postpartum women in Pawe district, Northwest Ethiopia.

Methods: Community based cross-sectional study design was employed from February to March 2019 in Pawe district. A stratified multistage sampling technique was used to select a total of 820 women in the extended postpartum period. Data were collected using a pretested interviewer administered questionnaire. A bivariable and multivariable logistic regression model was fitted to identify determinants of timely initiation of postpartum contraceptive among extended postpartum women. Adjusted Odds ratio (AOR) with $95 \% \mathrm{Cl}$ was computed to assess the strength and presence of an association. Variable with less than $0.05 p$-value considered as a significant determinant of contraceptive initiation.

Results: Out of the total participants about $37.2 \%[95 \% \mathrm{Cl}(34.0,40.5)]$ initiated postpartum contraceptive. Time return of menses [AOR $=18.32,95 \% \mathrm{Cl}(11.66,28.80)]$, postnatal care [AOR=7.8, 95\% bCl(3.98,15.44)], knowledge level regarding modern contraceptive methods [AOR=3.0, 95\% $\mathrm{Cl}(1.40,6.59)]$, time of resumption of sexual intercourse [AOR=2.1,95\% $\mathrm{Cl}(1.327,3.21)$, husband approval to use contraceptive $[\mathrm{AOR}=2.45,95 \% \mathrm{Cl}(1.42,4.22)$, antenatal care $[\mathrm{AOR}=2.1,95 \% \mathrm{Cl}(1.13,3.76)$, place of delivery at institution [AOR=2.0,95\% $\mathrm{Cl}(1.22,3.39)]$, and got family planning counseling at delivery [AOR=2.34, 95\% $\mathrm{Cl}(1.22,4.49)]$ were factors associated with timely initiation of postpartum contraceptive.

Conclusion and recommendation: The magnitude of timely initiation of postpartum contraceptive was low. This suggests strengthening the integration of postpartum contraceptive use with other basic maternal health services and improving knowledge of women in practicing timely initiation of postpartum contraceptive before engagement to risk activities of unintended pregnancy is important.

\section{Background}

Globally, 9 out of 10 women want 2 years after getting a child to prevent pregnancy, but $14 \%$ of women do not use contraception (1). The absence of priority for birth spacing and less use of postpartum modern contraceptive, result in poor maternal and newborn health outcomes (2).

Postpartum family planning is used to prevent unintended and closely spaced pregnancies in the first 12 months after giving birth (3). Depending on women reproductive plan, comprehensive postpartum family planning (PPFP) service aimed at helping women to choose the contraceptive method they want to use, to begin that method, and to continue to use it for 2 years or longer (1). Consequently, contraceptive use by women during this period is low, resulting in unintended pregnancies and unwanted childbearing (4).

There are factors like a combination of shorter periods of exclusive breastfeeding, early return of menstruation and early resumption of sexual intercourse increase the risk of unintended pregnancy (5). 
Women can be pregnant because of variability and unpredictability of time return of fertility after childbirth before the resumption of menstruation (1). The postpartum period offers multiple opportunities for health care providers to assist with family planning decision making, during the year following childbirth and women are more likely to engage with the health care system during antenatal care, delivery, postnatal care, and first-year infant immunizations (6). All women recommended and appointed to initiate postpartum contraceptive at or within the first 6 weeks of childbirth. The contacts between a health service provider and mothers after birth in the first 6 weeks are an opportunity to prevent unintended pregnancy and its consequence.

\section{Methods}

\section{Study design and setting}

A community based cross-sectional study was carried out from February to March 2019, in Pawe District. Pawe district is found in Metekel zone, Benishangul Gumuz regional state, Northwest Ethiopia. Administratively the district is structured into 2 urban and 19 rural kebeles (a total of 21 Kebeles), the smallest administration unit. Based on the 2011 district based census, a total of 76,006 people $(37,552$ females and 38,454 males) and 22,531 reproductive age group live in the Pawe District (projection). The district has one general hospital, 4 health centers, 15 health posts, and 3 private clinics. A mixed farming, crop and livestock production, is the major the livelihood of the population.

\section{Population and Sample}

The study population was all women in the extended postpartum period or those who gave live birth from 6 weeks of birth up to 12 months were included. The sample size was determined using both a single and double population proportion with the assumption of $95 \%$ confidence level, the margin of error of $4 \%$, taking 31.7\%(7) expected prevalence from the previous study in Ethiopia, design effect 1.5 and nonresponse rate of $10 \%$ was used. This makes the final calculated sample size became 858 .

\section{Data collection}

A structured questionnaire first prepared in English and translated to the local language (Amharic) was used to collect data. The questionnaire was pretested among 43 women in the kebeles that are away from the study population. Data quality was maintained via training of the data collectors and supervisors, pretesting of data collection tools and close supervision by supervisors and principal investigators.

\section{Data processing and management}


After completing data collection, the data were cleaned, coded and entered into a computer using Epi-info window version 7.0.then exported to Statistical Package for Social Science (SPSS) Windows version 20 for further analysis. Descriptive statistics, such as frequencies and percentages were computed to describe the study population in relation to relevant variables. Respondents were scored for a set of attitude-related Likert Scale questions ranging from the lowest 18 points up to 50 the maximum, then the median was 37 taken as the cut of point and those who scored below median classified as unfavorable attitude. Bivariable logistic regression using the enter method was used to analyze the association between individually the independent variable to the dependent variable. Variables found to have an association with the dependent variable less than $0.2 \mathrm{p}$-values at bivariable logistic regression model were considered for multivariable logistic regression using enter method for controlling the possible effects of confounders and finally the variables which have significant association was identified on the bases of Odds Ratio (OR), with $95 \% \mathrm{Cl}$ and p-value $<0.05$. Finally, text, table, and graph were used to present the results.

\section{Ethical consideration}

Ethical clearance was obtained from the University of Gondar Ethical Review board and Communication with the different official administrators was made through formal letter obtained from the University of Gondar. Supporting letter was also obtained from Pawe district health office. Permission was secured from Pawe district of all Selected Kebeles. Written consent was obtained from the study participants after telling the objective of the study. All the study participants were informed about the purpose of the study. If they feel discomfort on the interview they were informed that they can stop at any time. They also told that the information obtained from them was treated with complete confidentiality.

\section{Result}

\section{Socio-demographic characteristics}

From a total of 858 estimated sample, 820 extended postpartum women were recruited and interviewed with the response rate of $95.6 \%$. The women's mean $\pm S D$ age was $28 \pm 4.41$ years, the majority of the study participants $555(67.7 \%)$ were in the age group of 25-34 years. Most 797 (97.2\%) were married and nearly two-thirds of (63.9\%) had no formal education and seven hundred two (85.6\%) were housewives. About $48.2 \%$ of participants were Orthodox Christians religion followers (Table 1 ).

\section{Partner communication and decision}

Regarding partner communication and discussion of the respondents, 591(74.1\%) of them have discussed with their husband on a number of the children they desired to have in the future. From those who have discussed with their husband, more than half (59.8\%) of them decided together. From $73.1 \%$ of the respondents who have discussed with their husband on importance modern contraceptive utilization 
about $72.2 \%$ of them decided together. In terms of husband's approval on modern contraceptive utilization, $65.2 \%$ of the respondents reported that their husbands approved to utilize modern contraceptive methods.

\section{Knowledge and attitude towards modern contraceptive methods}

Nearly all participants ( $98.5 \%$ ) heard of modern contraceptive methods and 79.8 percent had good knowledge of the benefits of modern contraceptive use scored above or equal to $50 \%$. (Table 2 ).

Regarding attitudes of the respondents towards the benefits of contraceptive utilization more than half $(51.1 \%)$ of them had an unfavorable attitude (Table 3 ).

\section{Characteristics of the respondents related to maternal health service}

Regarding the respondents' maternal health service utilization characteristics, about $651(79.4 \%)$ of them had the previous history of using modern contraceptive methods before last pregnancy and $76.8 \%$ of them have attended antenatal care during their last pregnancy. Five hundred ten (62.2\%) gave their last birth at home. Concerning postnatal care service utilization, $70.2 \%$ of the respondents attended postnatal clinic after their last delivery (Table -4$)$.

\section{Reproductive history related factors of the respondents}

In aspects of the respondents ' reproductive characteristics, about $39 \%$ of them were above 6 months postpartum period, $37.3 \%$ had a history of two to three pregnancies and $78.3 \%$ delivered their last child with two years and above after previous birth. From a total 694 (84.6\%) women who had seen menses after their last delivery, 359 (43.8\%) of them menses returned in the first 6 weeks and from 765(93.3\%) women who had resumed sexual intercourse $45.4 \%$ of them started within the first 6 weeks of delivery.

\section{The magnitude of timely initiation of postpartum contraceptive}

This study revealed that the magnitude of timely initiated postpartum contraceptive was $37.2 \%$ with $95 \%$ $\mathrm{Cl}(34,40.5)$. The remaining $62.8 \%$ extended postpartum women lately initiated postpartum contraceptive.

The majority of contraceptive users used Injectable (76.8\%) followed by Implants (16.7\%) in relation to the choice of contraceptive methods mix (Fig. 2). 
Menses not returned, not resumed sexual intercourse, husband's disapproval, a far distance from the health facility, lack of preferred methods and others were the most common reasons for not initiating postpartum contraceptive timely (Fig.3).

\section{Factors associated with timely initiation of postpartum contraceptive}

From bivariable logistic regression analysis, educational level of wife, attending ANC, last pregnancy planned, place of delivery, got counseling at delivery, attending PNC, time return of menses, time of resumption of sexual intercourse, husband approval to use contraceptive, knowledge, and attitude towards benefits of using modern contraceptive methods were associated with timely initiation of postpartum contraceptive at $p$-value 0.2 .

In multivariable logistic regression analysis: women who had returned their menses within the first six weeks after birth, the odds of timely initiation of postpartum contraceptive were 18.32 [AOR $=18.32,95 \%$ Cl: $(11.66,28.80)]$ times higher than women who had returned their menses after six weeks. Women who had postnatal care follow up after their last delivery, the odds of timely initiation of postpartum contraceptive were 7.84 times [AOR $=7.84,95 \%$ Cl:(3.98,15.44)] higher than those who have never attended postnatal care after last delivery. Likewise, women who have attended antenatal care, the odds of timely initiation of postpartum contraceptive were 2.06 times [AOR $=2.06,95 \% \mathrm{Cl}(1.13,3.76)$ higher than counterparts. The odds of timely initiation of postpartum contraceptive in women who had good knowledge about a contraceptive were 3.04 times $[A O R=3.04,95 \% \mathrm{Cl}(1.40,6.59)$ higher than those who had poor knowledge. The odds of timely initiation of postpartum contraceptive in women who had husband approval to use contraceptive after delivery were 2.45 times [AOR $=2.45,95 \% \mathrm{Cl}:(1.42,4.22)$ ] higher as compared to their counterpart. The odds of timely initiation of postpartum contraceptive in women who have resumed sexual intercourse in the first six weeks were 2.06 times [AOR $=2.06,95 \% \mathrm{Cl}$ $(1.33,3.21)$ higher than counterparts. The odds of timely initiation of postpartum contraceptive in women who have delivered in the institution were 2.03 times [AOR $=2.0395 \% \mathrm{Cl}:(1.22,3.39)]$ higher than those who have delivered home. The odds of timely initiation of postpartum contraceptive in women who have counseled at delivery about a postpartum contraceptive were 2.34 times[AOR $=2.34,95 \% \mathrm{Cl}(1.22,4.49)$ higher than the counterparts.(Table. 5)

\section{Discussion}

This study revealed that the magnitude of timely initiation of postpartum contraceptive among extended postpartum women was $37.2 \%$ [95\% $\mathrm{Cl}(34,40.5)]$. This finding is consistent with the study conducted in Nigeria (38\%) (8) and India (34.7\%) (9)

However, this finding was higher than studies conducted in Aroressa District, Southern Ethiopia (31.7\%) (7) and Togo (17.3\%) (10). This difference might be due to improvement in maternal health service and 
health seeking behavior, the difference in the study area as well as the socio-economic status and demographic characteristics of the study participants.

The most commonly used contraceptive methods in the current study were injectable (78.8\%) and followed by Implant (16.7\%). These differences in percent distribution by the method were in line with studies conducted in Ethiopia (7)(11). This would be ascribed to the preferences of customers for a particular method as well as the accessibility and availability of the methods selected.

The study also identified factors affecting the timely initiation of postpartum contraceptive. The finding showed that time return of menses after delivery was one of the predictors for initiation of postpartum contraceptive timely. Women who had resumed menses in the first six weeks after delivery associated with increased initiation postpartum contraceptive than those women who had delayed the return of menses beyond six weeks of delivery. This might be due to: the return of menses after delivery alarm women probability of getting pregnant and this favors the initiation of postpartum contraceptive. This finding appeared to be consistent with studies done in Debre Berhan Town(12), Addis Ababa (13) and Butajira Health and Demographic Surveillance Site(14), Ethiopia and central Africa (10).

Women who had maternal health services such as ANC and PNC follow up associated with increased initiation of postpartum contraceptive compared to those who had no follow up. This finding was consistent with studies conducted in Nigeria(15)and Aksum (11), Aroressa District (7), Kebribeyah Town(16), Ethiopia. Women who had frequent visits during ANC and PNC had more exposure to information and had awareness of birth spacing by using contraceptives after each birth may be an additional explanation.

Another factor found to encourage the initiation of postpartum contraceptive was husband approval to use a contraceptive. Women who had approved by their husband to use contraceptive after delivery were 2.45 times higher to initiate postpartum contraceptive timely than their counterparts. This is likely due to women who had their husband's approval to start postpartum contraception soon with confidence without fear. This relationship is consistent with findings reported by other studies in Ethiopia (17)

Place of delivery was significantly associated with timely initiation of postpartum contraceptive. The odds of timely initiation postpartum contraceptive in women who had delivered in a health institution were two times higher than women delivered in the home. The explanation for this finding is that the provision of facilities delivery remains significant opportunities to provide access to postpartum family planning messages and to give women different methods of contraception. This finding, therefore, highlights the need for inclusion of services within the public sector in order to take benefit of the delivery to boost the take-up of family planning during the critical postpartum period. This finding is supported by a study done in India (18).

Women who had counseled at delivery about a postpartum contraceptive, the odds of timely initiation postpartum contraceptive were 2.3 times higher than the counterparts. This may be because women who 
are received postpartum contraceptive counseling during delivery might be highly motivated to use modern contraceptive methods. This relationship supported by a study done in Ethiopia (19).

Women who had resumed sexual intercourse during the first six weeks, the odds of timely initiation of postpartum contraceptive were 2.1 times higher than women resumed after six weeks. The possible explanation for this might be women who resumed sexual intercourse likely to initiate modern contraceptive timely consider the risk of pregnancy. This finding association supported by studies done in Ethiopia (11)(12).

Women who had adequate knowledge about a modern contraceptive, the odds of timely initiation of postpartum contraceptive were 3.04 times higher than women with poor knowledge. This might be women who have good knowledge of modern contraceptive, who timely practice contraceptive initiation owing to fear of unintended pregnancy. This finding consistent with the study done in Ethiopia (11)(20).

Finally, at the $95 \%$ significance level, other covariates like; Educational level of wife, Attitude of the respondent towards the benefit of using modern contraceptives and Last pregnancy planned were not significantly associated with timely initiation of postpartum contraceptive.

\section{Limitation of the study}

The limitation of this study did not address all health system-related factors that affect timely initiation of postpartum contraceptive. As well as recall bias regarding women who had lost appointment cards of family planning to check the date of start.

\section{Conclusion}

This study revealed that the magnitude of timely initiation of postpartum contraceptive was low. Time return of menses, postnatal care, knowledge level of respondent, time resumption of sexual intercourse, husband approval to use a contraceptive, antenatal care, place of delivery and counseled at delivery about postpartum contraceptive was an important predictor for timely initiation of postpartum contraceptive.

\section{List Of Abbreviations}

ANC: Antenatal Care, EDHS: Ethiopian Demographic and Health survey, EPFP: Extended Postpartum Family Planning, FP: Family Planning, HH: House Hold, IPH: Institute of Public Health, MNCH: Maternal Neonatal and Child Health, PNC: Postnatal Care, PPFP: Postpartum Family Planning, IUCD: Intra Uterine Contraceptive Device, SDP: Sustainable Development Program, UOG: University of Gondar, WHO: World Health Organization.

\section{Declaration}




\section{Ethics approval and consent to participate}

Ethical clearance was obtained from the University of Gondar ethical review board and communication with the different official administrators was made through formal letter obtained from the University of Gondar. Supporting letter was also obtained from Pawe district health office. Permission was secured from Pawe district of all selected kebeles. Oral consent was obtained from the study participants after telling the objective of the study. All the study participants were informed about the purpose of the study. If they feel discomfort on the interview they were informed that they can stop at any time. They also told that the information obtained from them was treated with complete confidentiality. The data collection procedure was anonymous and their privacy was kept.

\section{Consent for publication}

Not applicable

\section{Availability of data and material}

Data is available from the corresponding author upon request.

\section{Competing interests}

The authors declare that they have no competing interests.

\section{Funding}

The study was funded by the Ethiopian Minister of Education, Ethiopia. The funder has no role in study design, data collection, and analysis, interpretation of data, the decision to publish, or preparation of the manuscript.

\section{Authors' contributions}

HY, KTT participated to advise, visualization, validation the whole work and prepared the manuscript. DNJ took part in funding acquisition, data collection, supervision and software, and other resources. All authors read and approved the final manuscript.

\section{Acknowledgments}


We are thankful to data collectors, supervisors, Pawe district Health Office workers for their cooperation and support.

\section{Reference}

1.A. G. Best practice in postpartum family planning. leading safe choice June 2015

2.Ahmed S, Norton M, Williams E, Ahmed S, Shah R, Begum N, et al. Operations research to add postpartum family planning to maternal and neonatal health to improve birth spacing in Sylhet District, Bangladesh. Global Health: Science and Practice. 2013;1(2):262-76.

3.Organization WH. Programming strategies for postpartum family planning, 2013. Geneva, Switzerland: WHO. 2014.

4.USAID W. Update on family planning in Sub-Saharan Africa. Repositioning family planning: guidelines for advocacy action USAID, Africa's Health in. 2010.

5.Borda MR, Winfrey W, McKaig C. Return to sexual activity and modern family planning use in the extended postpartum period: an analysis of findings from seventeen countries. African journal of reproductive health. 2010;14(4).

6.WPP D, and MICS. Opportunities for Family Planning Programming in the Postpartum Period in Ethiopia. 2015.

7.Dona A, Abera M, Alemu T, Hawaria D. Timely initiation of postpartum contraceptive utilization and associated factors among women of child bearing age in Aroressa District, Southern Ethiopia: a community based cross-sectional study. BMC public health. 2018;18(1):1100.

8.Ujah OI, Ocheke AN, Mutihir JT, Okopi JA, Ujah IA. Postpartum contraception: determinants of intention and methods of use among an obstetric cohort in a tertiary hospital in Jos, North Central Nigeria. 2017.

9.Mody SK, Nair S, Dasgupta A, Raj A, Donta B, Saggurti N, et al. Postpartum contraception utilization among low-income women seeking immunization for infants in Mumbai, India. Contraception. 2014;89(6):516-20.

10.Pleah T, Hyjazi Y, Austin S, Diallo A, Dao B, Waxman R, et al. Increasing use of postpartum family planning and the postpartum IUD: early experiences in West and Central Africa. Global Health: Science and Practice. 2016;4(Supplement 2):S140-S52.

11.Abraha TH, Teferra AS, Gelagay AA. Postpartum modern contraceptive use and associated factors in Northern Ethiopia. Epidemiology and Health. 2017.

12.Demie T, Demissew T, Huluka T, Workineh F, Libanos H. Postpartum Family Planning Utilization among Postpartum Women in Public Health Institutions of Debre Berhan Town, Ethiopia. J Women's Health Care. 
2018;7(426):2167-0420.1000426.

13.Gebremedhin AY, Kebede Y, Gelagay AA, Habitu YA. Family planning use and its associated factors among women in the extended postpartum period in Addis Ababa, Ethiopia. Contraception and reproductive medicine. 2018;3(1):1.

14.Fantahun M. Assessment of postpartum contraceptive adoption and associated factors in Butajira Health and Demographic Surveillance Site (HDSS), in Southern Ethiopia: ADDIS ABABA UNIVERSITY; 2015.

15.Do M, Hotchkiss D. Relationships between antenatal and postnatal care and post-partum modern contraceptive use: evidence from population surveys in Kenya and Zambia. BMC health services research. 2013;13(1):6.

16.Nigussie AT* GDaTG. Postpartum Family Planning Utilization and Associated Factors among Women who Gave Birth in the Past 12 Months, Kebribeyah Town, Somali Region, Eastern Ethiopia Journal of Women's Health Care. 2016.

17.Abraha TH, Belay HS, Welay GM. Intentions on contraception use and its associated factors among postpartum women in Aksum town, Tigray region, northern Ethiopia: a community-based cross-sectional study. Reproductive health. 2018;15(1):188.

18.Rajan S, Speizer IS, Calhoun LM, Nanda P. Counseling during maternal and infant health visits and postpartum contraceptive use in Uttar Pradesh, India. International perspectives on sexual and reproductive health. 2016;42(4):167.

19.Tefera L, Abera M, Fikru C, Tesfaye D. Utilization of Immediate Post-Partum Intra Uterine Contraceptive Device and Associated Factors: A Facility based Cross Sectional Study among Mothers Delivered at Public Health Facilities of Sidama Zone, South Ethiopia. J Preg Child Health 4: 326. doi: 10.4172/2376127X. 1000326 Page 2 of $8 \mathrm{~J}$ Preg Child Health, an open access journal ISSN: 2376-127X Volume 4. Issue 3. 1000326. one quarter. 2017;121(39.0):16-24.

20.Berta M, Feleke A, Abate T, Worku T, Gebrecherkos T. Utilization and associated factors of modern contraceptives during extended postpartum period among women who gave birth in the last 12 months in Gondar Town, northwest Ethiopia. Ethiopian journal of health sciences. 2018;28(2):207-16.

21.Tesfay F, Mesfin E, Gedefaw A. Resumption of Postpartum Sexual Intercourse and Use of Modern Contraceptive among In-Union Women in Addis Ababa: Cross Sectional Study. Ethiopian Journal of Reproductive Health. 2018;10(1):22-33.

22.Moore Z, Pfitzer A, Gubin R, Charurat E, Elliott L, Croft T. Missed opportunities for family planning: an analysis of pregnancy risk and contraceptive method use among postpartum women in 21 low-and middle-income countries. Contraception. 2015;92(1):31-9. 


\section{Tables}

Table 1: Socio-demographic and economic characteristics of the respondents in Pawe District, Northwest Ethiopia, 2019. 


\begin{tabular}{|c|c|c|}
\hline Variables and categories $(n=820)$ & Frequency & Percent \\
\hline \multicolumn{3}{|l|}{ Age } \\
\hline $18-24$ & 190 & 23.2 \\
\hline $25-34$ & 555 & 67.7 \\
\hline$>/=35$ & 75 & 9.1 \\
\hline \multicolumn{3}{|l|}{ Marital status } \\
\hline Single & 12 & 1.5 \\
\hline Married & 797 & 97.2 \\
\hline Divorced & 11 & 1.3 \\
\hline \multicolumn{3}{|l|}{ Religion } \\
\hline Orthodox & 395 & 48.2 \\
\hline Muslim & 203 & 24.8 \\
\hline Protestant & 222 & 27.0 \\
\hline \multicolumn{3}{|l|}{ Respondents' Educational level } \\
\hline No formal education & 524 & 63.9 \\
\hline Elementary school & 125 & 15.2 \\
\hline Secondary school & 98 & 12.0 \\
\hline Above secondary school & 73 & 8.9 \\
\hline \multicolumn{3}{|c|}{ Educational status of husband $(n=797)$} \\
\hline No formal education & 441 & 55.3 \\
\hline Elementary school & 65 & 8.2 \\
\hline Secondary school & 143 & 17.9 \\
\hline Above secondary school & 148 & 18.6 \\
\hline \multicolumn{3}{|l|}{ Occupation } \\
\hline Housewife & 702 & 85.6 \\
\hline Employer & 50 & 6.1 \\
\hline Merchant & 45 & 5.5 \\
\hline Student & 13 & 1.6 \\
\hline Daily laborer & 10 & 1.2 \\
\hline \multicolumn{3}{|l|}{ Residence } \\
\hline Urban & 159 & 19.4 \\
\hline Rural & 661 & 80.6 \\
\hline \multicolumn{3}{|l|}{ Ethnicity } \\
\hline Amhara & 544 & 66.3 \\
\hline Kembata & 131 & 16 \\
\hline Hadiya & 69 & 8.4 \\
\hline Oromo & 31 & 3.8 \\
\hline Tigray & 15 & 1.8 \\
\hline Others** & 30 & 3.7 \\
\hline
\end{tabular}


Monthly income (ETB)

\begin{tabular}{lll}
$<=500$ & 425 & 52.8 \\
\cline { 2 - 3 }$>500$ & 395 & 48.2 \\
\hline
\end{tabular}

** = Shinasha and Agew

Table 2: Knowledge level of the respondents towards modern contraceptive in Pawe district Northwest Ethiopia, 2019.

\begin{tabular}{lcc}
\hline Variables & frequency & percent \\
\hline know contraceptive used to prevent unwanted pregnancy & 754 & 92 \\
\cline { 2 - 3 } know contraceptive used to space pregnancy & 741 & 90.4 \\
\hline know contraceptive used to limit pregnancy & 734 & 89.5 \\
\hline Know condoms used to prevent pregnancy & 416 & 50.7 \\
\hline Can you become pregnant while breastfeeding & 614 & 74.9 \\
\hline Can a woman start contraception before the menstruation begins & 474 & 57.8 \\
\hline Know the side effects of contraceptives & 653 & 79.6 \\
\hline Know about early initiation of modern contraceptive after delivery is important & 522 & 63.7 \\
\hline Know that fertility resumed after stopping the contraceptive & 524 & 63.9 \\
\hline Anowledge level of respondents & 654 & 79.8 \\
\cline { 2 - 3 } & Adequate Knowledge & 166 \\
\hline
\end{tabular}

Table 3: Attitudes of the respondents towards modern contraceptives in Pawe district Northwest Ethiopia, 2019. 


\begin{tabular}{llllll}
\hline Variable & $\begin{array}{l}\text { Strongly } \\
\text { disagree }\end{array}$ & Disagree & Neutral & Agree & $\begin{array}{l}\text { Strongly } \\
\text { agree }\end{array}$ \\
\hline Adopt contraceptive in the future & $27(3.3 \%)$ & $243(29.6)$ & $15(1.8 \%)$ & $388(47.3 \%)$ & $147(17.9 \%)$ \\
& & & & & \\
$\begin{array}{l}\text { Encourage your friend to adopt } \\
\text { PPFP }\end{array}$ & $17(2.1 \%)$ & $94(35.9 \%)$ & $319(3.8 \%)$ & $356(43.4 \%)$ & $122(14.9 \%)$ \\
\hline $\begin{array}{l}\text { Contraceptive utilization helps a } \\
\text { mother to regain strength }\end{array}$ & & & & & \\
& & & & & \\
\hline
\end{tabular}

Table 4: Characteristics of the respondents related to maternal health services user in Pawe district Northwest Ethiopia, 2019. 


\begin{tabular}{llll}
\hline Variables & Categories & Frequency & Percent \\
\hline Attended ANC $(\mathrm{n}=820)$ & Yes & 630 & 76.8 \\
ANC visit(n=630) & 1 & 66 & 10.5 \\
\hline & $2-3$ & 193 & 30.6 \\
\hline Place of delivery(n=820) & $>=4$ & 371 & 58.9 \\
\hline Counseled at last delivery & Home & 510 & 62.2 \\
\hline Attended PNC (n=820) & Health institution & 310 & 37.8 \\
\hline PNC visit(n=576) & Yes & 547 & 66.7 \\
\hline & Yes & 576 & 70.2 \\
\hline Counseled at PNC visit(n=820) & 1 & 160 & 27.8 \\
\hline PNC at six week (n=576) & $2-3$ & 331 & 57.5 \\
\hline Heard about modern contraceptive before & $>=4$ & 85 & 14.7 \\
\hline Used modern contraceptive before & Yes & 495 & 60.4 \\
\hline Time of started postpartum contraceptives after birth & & 549 & 95 \\
\hline
\end{tabular}

Table 5: Bivariable and Multivariable analysis of factors associated with timely initiation of contraceptive in Pawe district, Northwest Ethiopia, 2019.

Figures 


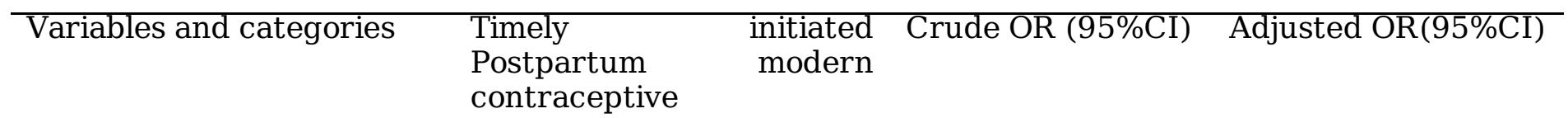

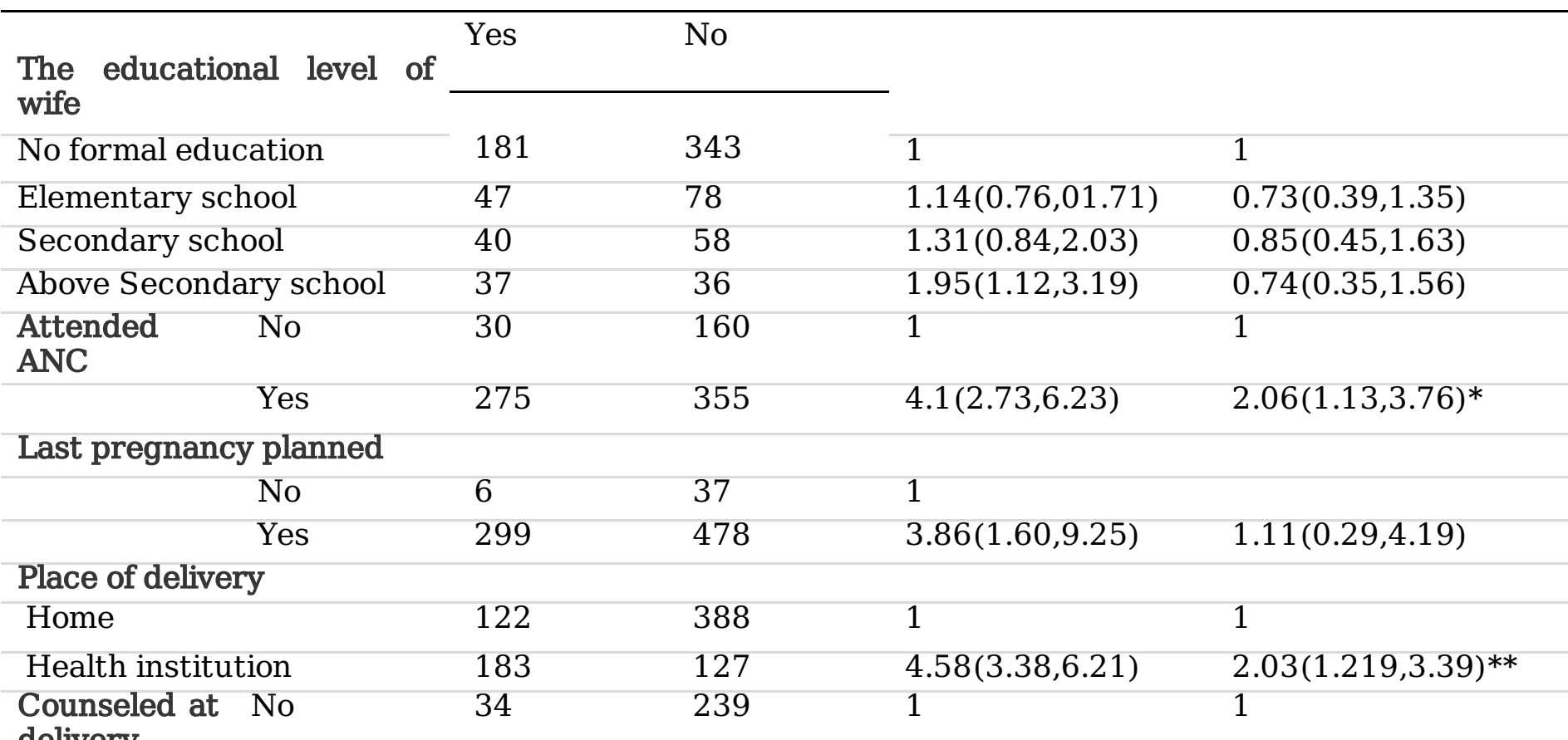

delivery

Counceld at

delivery

$\begin{array}{llllll} & \text { Yes } & 271 & 276 & 6.90(4.64,10.26) & 2.34(1.22,4.49)^{*} \\ \text { Attended } & \text { No } & 16 & 228 & 1 & 1\end{array}$

PNC

No

16

228

1

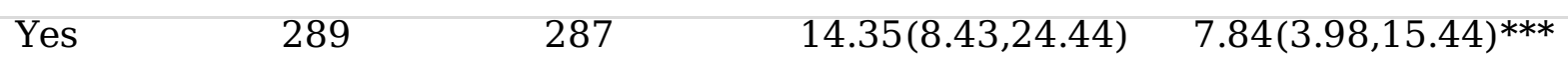

Time menses returned

$\begin{array}{lllll}>6 \text { weeks } & 54 & 407 & 1 & 1 \\ <=6 \text { weeks } & 251 & 108 & 17.52(12.19,25.17) & 18.32(11.66,28.8)^{* * *}\end{array}$

Time resumed sexual intercourse

$\begin{array}{lllll}>6 \text { weeks } & 130 & 318 & 1 & 1 \\ <=6 \text { weeks } & 175 & 197 & 2.17(1.63,2.89) & 2.06(1.33,3.21)^{* *}\end{array}$

Husband approval of the contraceptive

\begin{tabular}{llllll} 
No & 42 & 258 & 1 & 1 \\
Yes & & 263 & 257 & $6.29(4.35,9.09)$ & $2.45(1.42,4.22)^{* *}$ \\
$\begin{array}{lllll}\text { Knowledge } \\
\text { level }\end{array}$ & $\begin{array}{l}\text { Poor } \\
\text { Knowledge }\end{array}$ & 17 & 149 & 1 & 1 \\
\hline & Adequate & 288 & 366 & $6.89(4.08,11.58)$ & $3.04(1.40,6.59)^{*}$ \\
\hline $\begin{array}{l}\text { Attitude level } \\
\text { Non Favorable }\end{array}$ & 131 & 288 & 1 & 1 \\
\begin{tabular}{l} 
Postive atitude \\
\hline
\end{tabular} & & & & \\
\hline
\end{tabular}




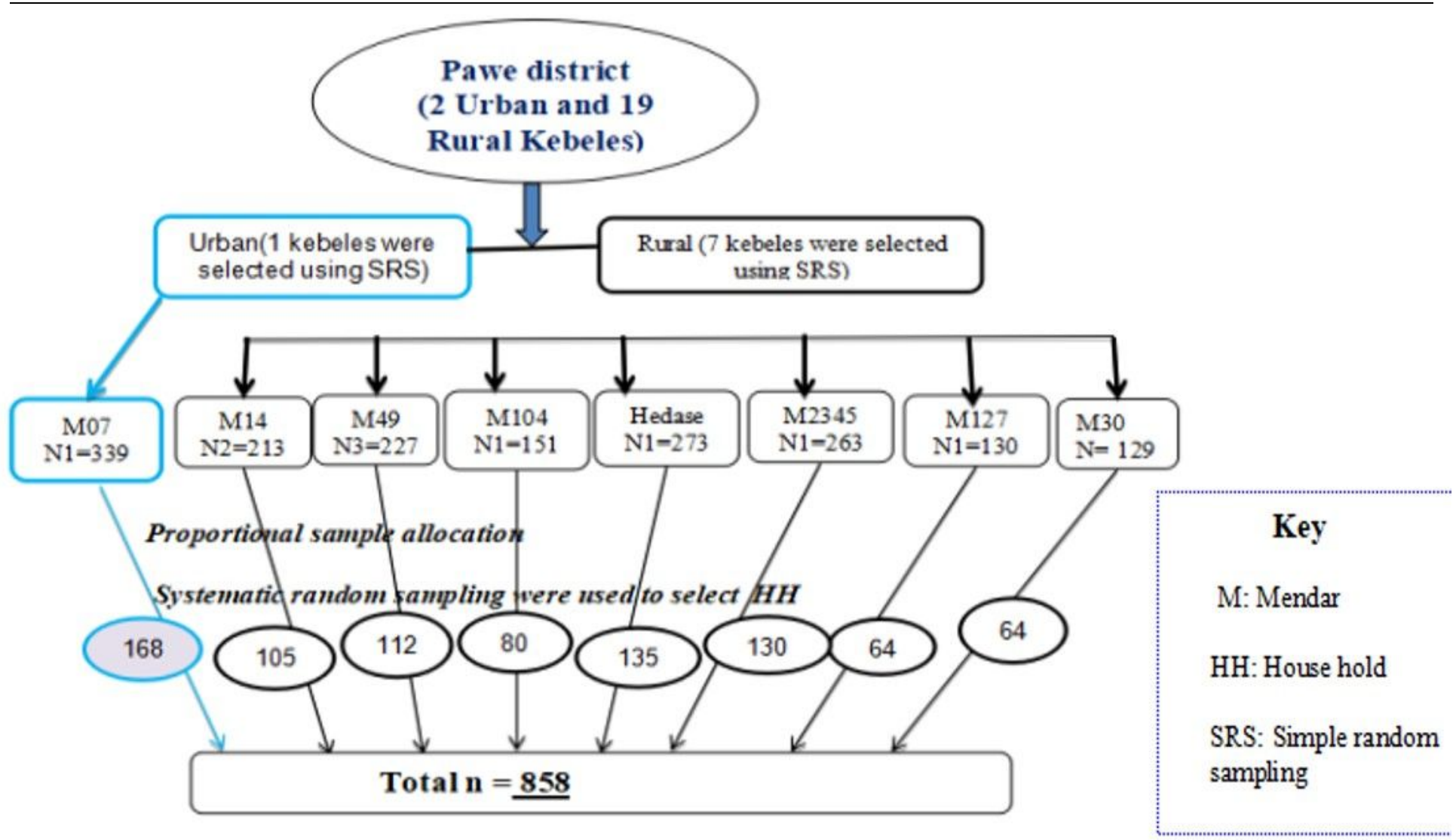

Figure 1

Diagrammatic presentation of the sampling procedure in Pawe district North west Ethiopia, 2019 

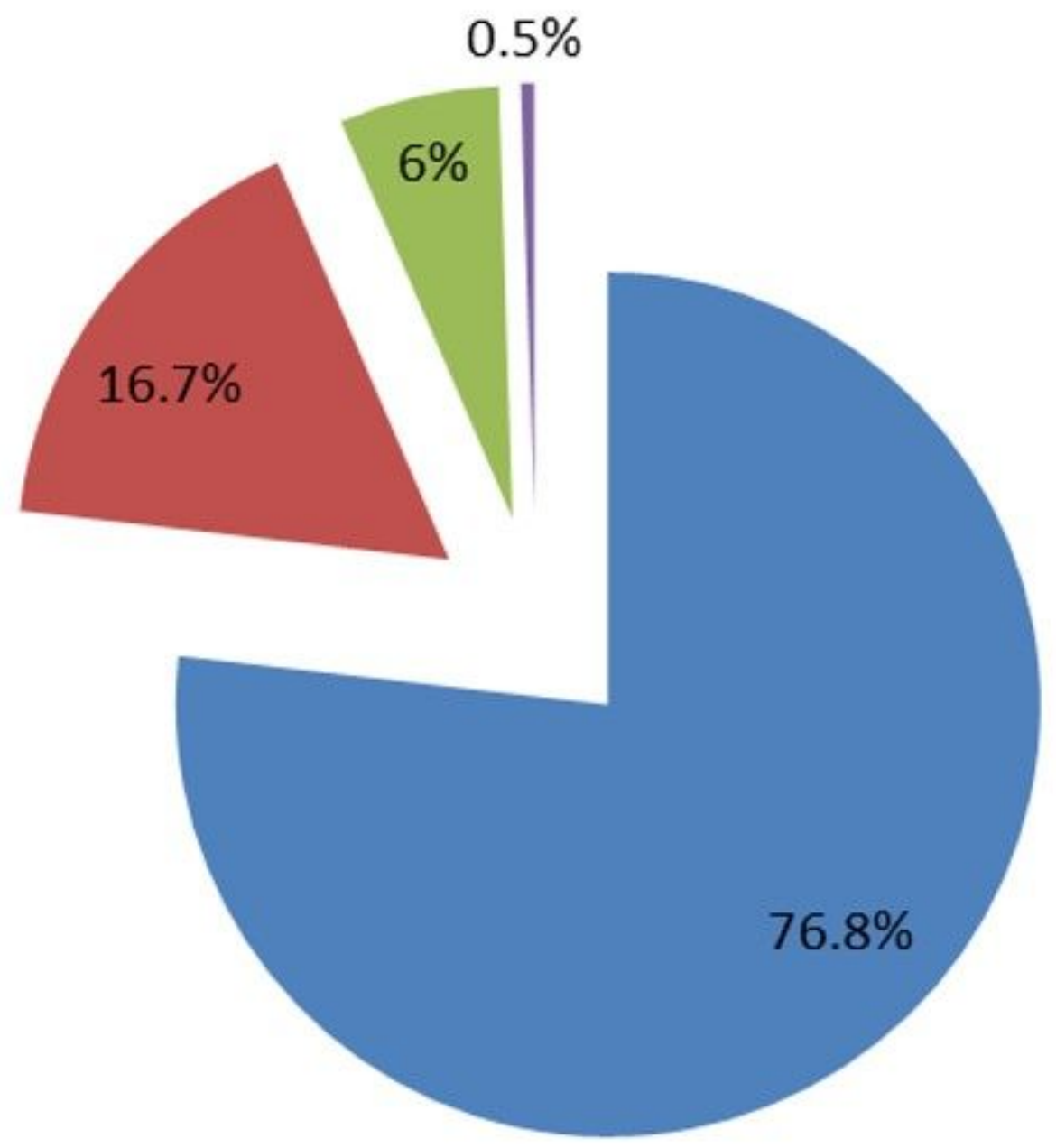

\section{Methods}

- Injectable

E Implants

aill

- IUCD

\section{Figure 2}

Percent distribution of Modern contraceptive user by the method in Pawe District, Northwest Ethiopia, 2019. 


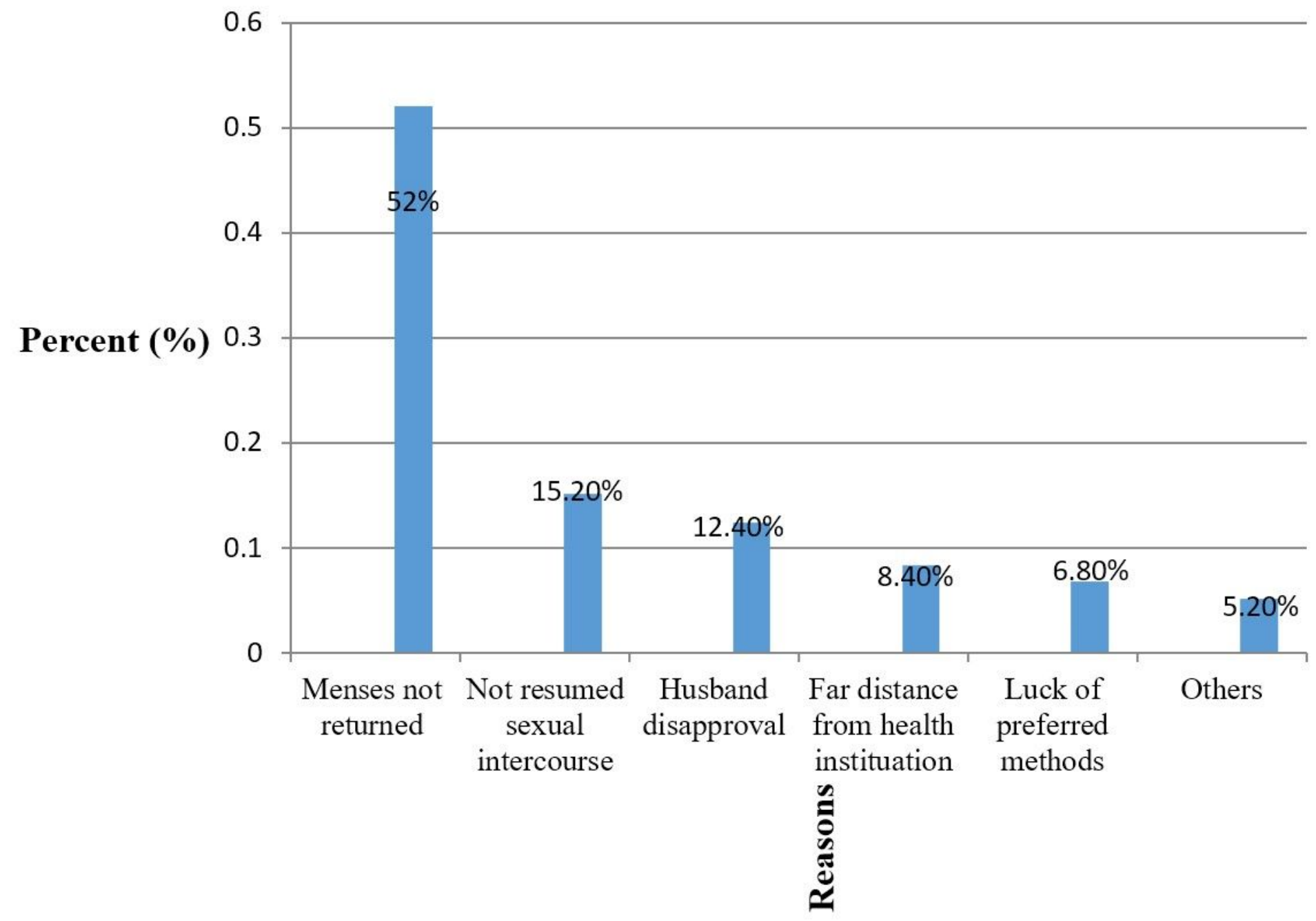

Figure 3

Others = Busy due to work and luck of the awareness. Reason of respondents not initiated postpartum modern contraceptive in the first 6 weeks of delivery in Pawe district Northwest Ethiopia, 2019 